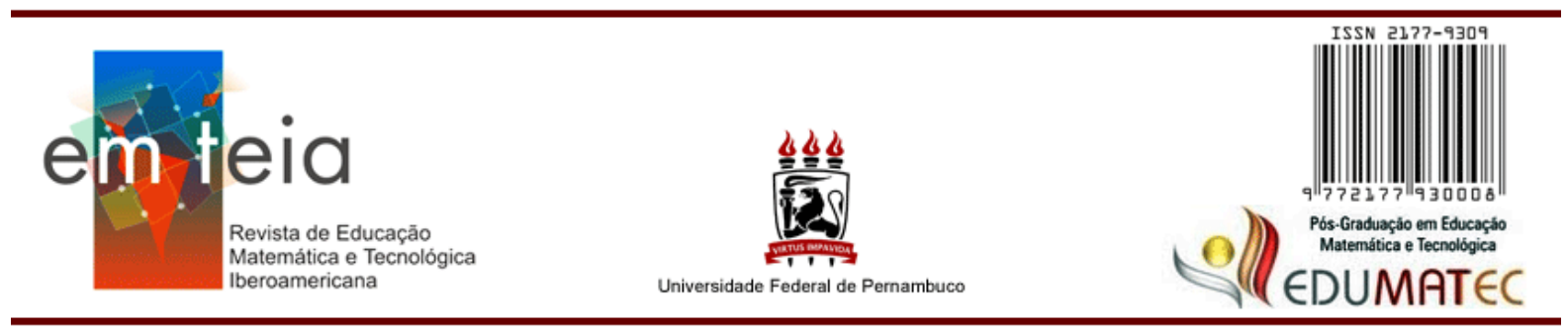

\title{
Docência-repouso:
}

\section{imagem platônico-aristotélica da docência em matemática contemporânea}

\author{
Resting-teaching: \\ platonic-aristotelic image of contemporary mathematics teaching \\ Suelen Assunção Santos \\ Doutora em Educação \\ UFRGS - RS - Brasil \\ suelen.santos@ufrgs.br
}

\begin{abstract}
Resumo
Qual imagem se atualiza quando se pergunta sobre a docência em matemática? A imagem da Docência-repouso, pautada na matriz filosófica platônico-aristotélica. A fim de remontar a imagem do pensamento e o plano de referência filosófico da docência em matemática que funciona como matriz de sentido para a área da Formação de Professores de Matemática, foi preciso um levantamento de opiniões e um levantamento bibliográfico. O levantamento de opiniões foi realizado com alunos da Matemática Licenciatura de duas Instituições de Ensino Superior Privadas do RS que responderam, por escrito, a seguinte questão: "O que é a docência em matemática? Qual o significado de docência? Que imagem é atualizada quando se pensa a docência?". O levantamento bibliográfico em livros visou mostrar o que se enuncia da Docência em matemática em meio a teóricos que são referência na área da Formação de Professores de Matemática. O discurso teórico foi necessário para fazer emergir as linhas de poder que regulam a Docência em matemática e para demarcar os limites impostos ao conceito de Docência na contemporaneidade. Conclui-se que a imagem da Docência em matemática contemporânea permanece no rastro das filosofias da representação platônica e aristotélica, cuja lógica dual e causal pretende a universalidade e a generalidade. Intitulou-se essa imagem de Docênciarepouso, e suas subjacentes categorias de docência-contemplação e docência-generalização.
\end{abstract}

Palavras-Chave: Platônico. Aristotélico. Docência. Matemática. Filosofia.

\begin{abstract}
What image is actualized when the subject is the teaching of mathematics? The image of the restingteaching based on the Platonic-Aristotelian philosophical matrix. In order to reassemble the image of the thought and the plane of philosophical reference of mathematics s teaching that works as a matrix of meaning for mathematics teacher education field, a bibliographical and a opinion survey were needed. The opinion survey was conducted with mathematics under-graduated students of two private higher education institutions from Rio Grande do Sul, Brazil. The participants provided writing answers for the following questions: What is teaching in mathematics? What is the meaning of teaching? What image is actualized when the subject is the teaching of mathematics? The bibliographical review study investigated what is enounced as teaching in mathematics among authors who are references in the mathematics teacher education field. The theoretical discourse was necessary to make emerge power lines that regulate teaching in mathematics and to demarcate the limits imposed at the concept of teaching in contemporary times. In conclusion, the contemporary image of the
\end{abstract}


teaching of mathematics remains in the trail of representation from Platonic and Aristotelian philosophies, whose dual and causal logic intends the universality and generality. That image was titled resting-teaching, and its underlying categories of contemplation-teaching and generalizationteaching.

Keywords: platonic, aristotelian, teaching, mathematics, philosophy.

\section{De que matéria se trata?}

Trata-se de pensar a docência em matemática. Trata-se da temática da Formação de Professores em Matemática como meio de pensar a docência em matemática. Trata-se de criar uma forma ou conceito ou imagem para a docência em matemática, não se trata de criar um consenso (DELEUZE; GUATTARI, 1992), nem trata-se de refletir, de contemplar, de comunicar.

Qual imagem se atualiza quando se pergunta sobre a docência em matemática?

Quando se enuncia a docência em matemática, em meio ao discurso educacional, alguns "desdobramentos meta-histórico das significações ideias" (FOUCAULT, 1979, p. 16) emergem: a docência pretende instruir, mostrar, ensinar, indicar, transmitir a verdade e é compreendida como questão de vocação que ultrapassa a mera profissão. A docência em matemática, portanto, é compromisso e é calcada na verdade. Esta aloca-se no conhecimento, no conteúdo científico matemático e pedagógico, que ora nos faz buscar na experiência prática, ora nos remete a buscar na teoria. A docência se constitui pelo ato de ensinar a verdade.

A imagem da docência em matemática foi construída por meio da demarcação de instantaneidades, ou ainda, de identidades fixas e estáveis de docências-sejam-lá-o-que-for que emergiram em meio a opiniões de Licenciandos em Matemáticsa e discursos teóricos da docência contemporânea. A partir dessas instantaneidades, foi possível compor o conceito de Docência-Repouso que se mostrou pautado na lógica dual e causal platônico-aristotélica. Mais especificamente, as docências que fazem parte do conceito de Docência-repouso são: a Docência-contemplação, sob um rastro platônico, e a Docência-generalização, sob um rastro aristotélico.

A imagem da Docência em matemática contemporânea é inaugurada pelo conceito intitulado Docência-repouso. Por intermédio do acúmulo de instantaneidades de docênciassejam-lá-o-que-for, mostra-se que a imagem da Docência pretende-se una e totalitária mediada pela identidade, sendo que a diferença não é pensada enquanto conceito. 
Apesar deste texto objetivar problematizar a matriz filosófica na qual a Docência contemporânea parece estar pautada, qual seja, a matriz das filosofias da representação platônico-aristotélica, a analítica não visa matar a velha estrutura para poder afirmar o novo da docência em matemática, pois não se pode viver sem referências, não se pode viver sem momentos de repouso, de paradas, sem a constituição de instantaneidades, de identidades, sem desacelerar e limitar o caos.

\section{Docência-repouso}

A Docência-repouso é uma imagem. O que o corpo consegue perceber é imagem, porque tudo é imagem e, quando percebe, forma. "A imagem não é encontrada, mas é fabricada, como resposta a problemas." (CORAZZA, 2012, p. 5).

A imagem Docência-repouso pretende-se totalitária, una e segura pelo acúmulo de ' $n$ ' instantaneidades: docência-crítica, "docência-construtivista" (SANTOS; SANTOS, 2014), docência-conformada, docência-lúdica, docência-reflexiva, docência-identidade, docênciainterdisciplinar, docência-coletiva, docência-colaborativa, docência-compartilhada, docênciaseja-lá-o-que-for etc. (SANTOS, 2015).

Necessário dizer que a Docência-repouso repousa suavemente sobre a imagem platônico-aristotélica das filosofias da representação: esta que subordina a diferença às potências do Uno, às relações do Análogo, às similitudes do Semelhante e à identidade do Mesmo, por intermédio de seu método da divisão. O ser ou a essência, segundo essa perspectiva, é mediado pela identidade e determinado por um sentido primeiro que regula todas as experiências. Para que o ser seja fundado, deve-se estar atento a determinadas presenças de características na matéria cambiante que, pelo intermédio da inteligência, distribuem e hierarquizam a matéria. Desse modo, o ser é o efeito de uma causa - primeiro dos dualismos (DELEUZE, 2006b). Vale ressaltar que o pensamento dual ou binário é um dos aspectos que dá sustentação à lógica da representação.

$\mathrm{O}$ efeito ou as identidades que o espaço apresenta ao entendimento são produtos semelhantes ao padrão. "Assemelhar significa uma referência primeira que prescreve e classifica. [...] A semelhança se ordena segundo o modelo que está encarregada de acompanhar e de fazer reconhecer" (FOUCAULT, 1988, p. 60).

A forma Docência-repouso é a identidade da Docência em matemática que pretende encarnar-se na atividade [de docentes]. Por tratar-se de uma identidade abstrata (incorpórea, atemporal e imutável) - continuando com a dualidade -, encerra padrões que ordenam e 
hierarquizam as experiências a assemelharem-se à referência prescrita. É o que se denominou docência-identidade ou Docência-Repouso.

O modelo de Docência-Repouso serve de critério para se distinguir, definir e selecionar as atividades que se assemelham ao modelo que se pretende ideal. A atividade docente, pois, só é Docência na medida em que imita o padrão - eis a eterna dualidade entre o ser e o não-ser. Duas metades da divisão que instauram o dessemelhante como a imagem degradada da diferença. Assim, há um primado da identidade no que seja o ser da Docênciarepouso, ou seja, nessa imagem de Formação de Professores de Matemática o ser da Docência permanece idêntico a si mesmo ao longo do tempo e do espaço, e resta para o pensamento [do docente] a tarefa do reconhecimento: reconhecer a ideia universal em cópias particulares; reconhecer a semelhança entre particulares e abstrair a generalidade.

O que se busca na Docência-repouso é proporcionar o conceito aos termos ou aos sujeitos, dos quais é ele afirmado. Os termos ou sujeitos não precisam ter uma relação de igualdade com o ser - nem conseguem, pois são de naturezas distintas.

Com base na lógica dual e causal platônico-aristotélica (SANTOS, 2015), a imagem da Docência em matemática é uma forma que representa um movimento que estratifica e repousa sobre a matéria, como um dever Docência $\mathrm{D}(\mathrm{x})$, em que a repetição opera como generalidade e se estabelece em estados de coisas que se sucedem previsivelmente. Por isso, a Docência-Repouso é movimento cinematográfico, falso movimento, movimento que não cria novos presentes e sim cria formas idênticas ao Mesmo conceito. Afinal, "com a imobilidade, mesmo indefinidamente justaposta a si mesma, não faremos nunca o movimento" (BERGSON, 2005, p. 300).

O movimento cinematográfico ganha animação na medida em que todas as fotografias, imagens estáticas, se desenrolam num sucessivo, mas descontínuo movimento, a fim de tornar-se uno pela totalização. As imagens estáticas da Docência-repouso - docência-crítica, docência-colaborativa, docência-seja-lá-o-que-for - também são imagens congeladas em coordenadas espaço-temporais (A, B, C, D, E, F etc.) que imitam sua própria lei $\mathrm{D}(\mathrm{x})$, conforme figura 1 , e que ganham movimento por intermédio do conhecimento do docente. $\mathrm{O}$ conhecimento é de natureza cinematográfica. 


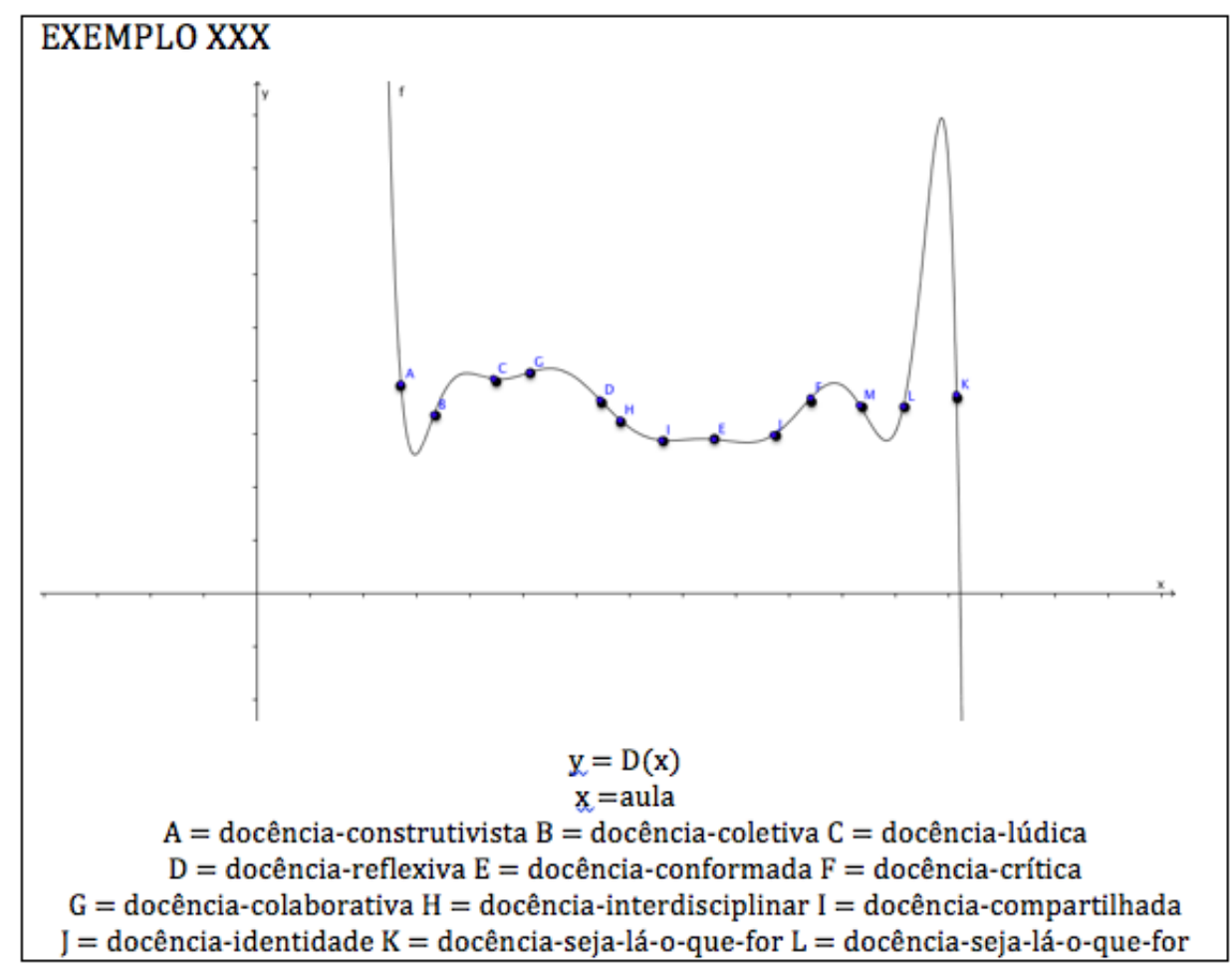

Figura 1: $\mathrm{D}(\mathrm{x})$ - docência-repouso

Fonte: (SANTOS, 2015, p.88)

As instantaneidades A, B, C, etc. dizem respeito aos ' $\mathrm{n}$ ' possíveis da Docênciarepouso, em que $n \rightarrow \infty$. Se 'n' são os possíveis, então não são necessariamente reais, mas possuem potencial de realização. Apenas realizam-se um por vez e, por isso, não coexistem no tempo, o que demarca a descontinuidade do movimento da Docência-repouso: ora realizase $\mathrm{A}$, ora realiza-se $\mathrm{B}$, ora realiza-se $\mathrm{C}$, etc., e $\mathrm{A}$ é não-B, e B é não-C, etc. A Docênciarepouso possui uma extensão de instantâneos que não duram, são tempos presentes da atividade docente e representam apenas tempos espacializados numa sucessão interrupta.

A Docência-repouso até considera que, entre A e B, haja uma infinidade de outras docências-sejam-lá-o-que-for. No entanto, todas essas infinidades estão, desde já, previamente asseguradas a imitarem sua própria lei: estarão, inevitavelmente, realizadas sobre a curva $\mathrm{D}(\mathrm{x})$. Para que o movimento seja alcançado, todavia, Bergson (2005) menciona que deve-se reinserir na mudança, não entre estados sucessivos de repouso. Para tentar reconstituir a mudança a partir da absurda proposição de que "o movimento é feito de imobilidades" (BERGSON, 2005, p. 333), pode-se aproximar tanto quanto possível dois estados consecutivos em repouso, que experimentar-se-á "a decepção da criança que, aproximando uma da outra suas duas mãos abertas, quer esmagar a fumaça. O movimento escorregará para o intervalo [...]" (BERGSON, 2005, p.333), no caso de D(x), para o intervalo entre A e B. 
A Docência-repouso desconsidera que estes instantâneos poderiam extrapolar a previsibilidade de sua própria lei, de sua própria curvatura $\mathrm{D}(\mathrm{x})$, constituindo outras linhas de força para a Docência em matemática. Esses instantâneos que escapam à curva $\mathrm{D}(\mathrm{x})$ seriam a imagem da diferença, a imagem sem semelhança com o modelo. $\mathrm{D}(\mathrm{x})$ repete instantâneos que reproduzem infinitamente o Mesmo conceito. A operação de individualização da Docência ou, se quisermos dizer de outra forma, a operação de máxima caracterização e especificação da Docência, dá-se pelo movimento interrupto de repetição da generalidade. Falso movimento.

Podemos considerar que a individualidade diz respeito a um problema de identidade e que sua analítica ficou abalada desde que foi considerada a existência de um movimento que desce de um pré-individual ao indivíduo. Nesse sentido, fica comprometida e mostra-se fragilizada "a unidade do ser (síntese, sujeito), como característica do ser individuado, quanto a identidade [...] do indivíduo, já que este é apenas uma fase do ser, posterior à operação de individuação" (CORAZZA, 2008, p. 95).

A operação de individuação dá-se pelo movimento de repetição da diferença e não como repetição do semelhante, conforme se dá no campo da Docência-Repouso. Dessa forma, a diferença, como no campo da filosofia categorial, não é pensada enquanto conceito. No máximo, é pensada como um conceito reflexivo, que reflete a diferença de uma individualidade 'A' em relação a outra 'B' - diferença externa aos termos, ou, entre A e o modelo $\mathrm{D}(\mathrm{x})$.

As quatro ilusões da filosofia da representação submetem a diferença a um lugar maldito de negação ao modelo ou de insuficiência de características, porém, o processo de diferenciação (DELEUZE, 2012) não está entre dois presentes previsíveis, entre extensos que se assemelham, entre semelhantes: afinal, "só o que se parece difere"? (DELEUZE, 2009). A diferença apenas escapa de ser um conceito reflexivo para tornar-se catastrófico na medida em que designa "rupturas de continuidade na série das semelhanças" ou "falhas intransponíveis entre estruturas análogas" (DELEUZE, 2006a, p. 65). Como “catástrofe, a diferença não dará, justamente, testemunho de um fundo rebelde irredutível que continua a agir sob o equilíbrio aparente da representação orgânica?” (DELEUZE, 2006a, p. 65). Sobre esse fundo contínuo, a Docência-repouso não se abre, e, talvez, por isso, não haja espaço para a verdadeira diferença e movimento na/da docência em matemática. O conceito de diferença na Docência-repouso se contenta "em inscrever a diferença na quase-identidade dos conceitos determináveis mais gerais" (DELEUZE, 2006a, p. 64). 
O ser da Docência-repouso é ora universal, ora geral. Em outras palavras, a essência da Docência-repouso ora se estabelece em premissas transcendentais que são tomadas como ideais, ora se estabelece em abstrações generalizadas a partir de experiências particulares. Sabe-se o que é por meio da semelhança, oposição, analogia e contrariedade - quádruplo clássico das filosofias da representação. Assim, a diferença está sempre em relação ao não-ser e, portanto, o ser não é em relação ao que ele é.

Por exemplo, em relação aos números primos: a matemática recorre à materialidade do objeto "1" para que o inteligível seja alcançado, como se fosse um sonho passível de contemplação - “isto não é um número primo". A matéria deve fazer reconhecer sem hesitação e equívoco o que ela representa: e o faz, pois não há contradição entre o objeto "1" e o conceito "isto não é um número primo". Assim o é para a Docência-Repouso: para que o ser da Docência em matemática seja alcançado pelo docente, há de se reconhecer aquelas docências-sejam-lá-o-que-for que a representam. Cabe ao docente, enquanto causa da Docência-Repouso, uma boa vontade para reconhecer: inaugura-se a tratativa de que "a culpa da Docência é do docente". Para esta analítica, todavia, pensamento difere de [re]conhecimento e de reflexão, visto que estes últimos são considerados conscientes e voluntários. Conforme Corazza (2012, p. 3), "Pensamos sem o saber, até contra os saberes; e que, por isso, pensar é um ato involuntário, seja no seu surgimento seja no seu criar. [...] pensar é uma experiência de raridade".

Sim. No escopo das filosofias da diferença, pensar não é inato, não é um exercício natural (da docência), nem da docência em matemática. Portanto, pensar a docência só pode se dar por meio de uma violência, que acontece em decorrência da exterioridade dessemelhante das relações. "O privilégio da exterioridade [...] é a base [...] para a invenção de inauditas combinações, para a arte do encontro e da composição entre as caixas que abriu, saqueou e para as quais inventou segredos" (HEUSER, 2010, p. 38).

Para que se inventem segredos para a docência em matemática, há de se fazer combinações entre termos, portanto, os termos são necessários. Realizar combinações é distinto de ter um método de obtenção de verdades, pois realizar combinações é tarefa do próprio "autor"; autor enquanto "princípio do agrupamento discursivo" (FOUCAULT, 19692015).

Pode-se dizer que o "método" da repetição foi o escolhido para compor o conceito de Docência-repouso no limite da lógica dual e causal platônico-aristotélica. A repetição por reprodução foi necessária para compor o conceito de Docência-Repouso e para compor suas 
duas subjacentes categorias, quais sejam, a Docência-contemplação e a Docênciageneralização. Para que estas subjacentes categorias aparecessem foi necessário um levantamento bibliográfico e um levantamento de opiniões. O levantamento de opiniões foi realizado com (meus) 47 alunos da Matemática Licenciatura de duas Instituições de Ensino Superior Privadas do RS que responderam, por escrito, a seguinte questão: “O que é a docência em matemática? Qual o significado de docência? Que imagem é atualizada quando se pensa a docência?" O levantamento bibliográfico em livros visou mostrar o que se enuncia da docência em matemática em meio a teóricos que fazem parte das referências básicas na área da Formação de Professores de Matemática, perspectivado pela Educação Matemática. Os livros foram escolhidos porque compuseram as bibliografias básicas de disciplinas de Educação Matemática ministradas por esta professora. O discurso teórico foi necessário para fazer emergir as linhas de poder que se mostram discursivamente como regimes de verdade para a Docência em matemática e para demarcar os limites impostos ao conceito de docência na contemporaneidade. Repetiu-se por reprodução para dar "limite" e nomear as instantaneidades docência-coletiva, docência-lúdica, docência-reflexiva etc. Considera-se que "Todo limite é ilusório, e toda determinação é negação, se a determinação não está numa relação imediata com o indeterminado" (DELEUZE; GUATTARI, 1992, p. 156).

Os enunciados discursivos que compõem as docências prescritas e desejáveis, quais sejam, a Docência-Contemplação e a Docência-Generalização,

[...] estão pautadas em discursos verdadeiros imbricados na educação matemática e que funcionam como normalizadores de formas de ser docente. Essas possibilidades de composições estéticas serão apresentadas a partir de recortes de discursos frequentes na educação matemática que possibilitam legitimar e produzir maneiras de ser docente. (SANTOS; SANTOS, 2014, p. $3)$.

Garimpou-se em livros da área da Educação Matemática o que se entendia por docência. Após copiar excertos que tratavam do que seja a docência em matemática ou excertos que mencionavam as demandas da docência em matemática, agrupou-os pelo método de assemelhamento. Por recorrência discursiva, pode-se dizer que os agrupamentos foram realizados e por assemelhamento foram-se inventando categorias analíticas (docências-crítica, docência-reflexiva, docência-lúdica, docência-seja-lá-o-que-for).

O trabalho de composição conceitual, no caso deste trabalho o conceito de Docênciarepouso, não possui uma metodologia previamente conhecida, mas a metodologia é o próprio 
trabalho de composição conceitual. Portanto, nunca se sabe, de antemão, qual será o resultado final, pois o imprevisível adentra-se em meio à escrita e desnaturaliza o naturalizado, fazendo esquecer o que anteriormente diziam os conceitos, fazendo inventar novos sentidos para o conceito de docência. Repetem-se os clichês da docência para raspá-los e devolvê-los ao "caos", admitindo que há um "entre", um intervalo, um meio de contato entre eles.

[...] a primeira diferença está na atitude respectiva da ciência e da filosofia com relação ao caos. Define-se o caos menos por sua desordem que pela velocidade infinita com a qual se dissipa toda forma que nele se esboça. É um vazio que não é um nada, mas um virtual, contendo todas as partículas possíveis e suscitando todas as formas possíveis que surgem para desaparecer logo em seguida, sem consistência nem referência, sem consequência. É uma velocidade infinita de nascimento e de esvanecimento. Ora, a filosofia pergunta como guardar as velocidades infinitas, ganhando ao mesmo tempo consistência, dando uma consistência própria ao virtual. (DELEUZE; GUATTARI, 1992, p. 153).

Repetem-se os clichês da docência para tentar organizar novos agenciamentos, fazer outras combinações, para demarcar outros limites possíveis à docência. Considera-se que a linguagem estabiliza os "movimentos, mas que também faz lançar e constituir coisas do, com e no mundo, produzidas em campos de forças que disparam modos de dizer-ler-escrever relações, processos, objetos, sentidos...” (DALAROSA, 2011, p. 52).

A Docência-repouso carrega um rastro temporal e espacial que visa ser eterno e imutável, para ser verdadeiro. A repetição-reprodução das docências-sejam-lá-o-que-for visam à repetição do Mesmo conceito de docência - Docência-Repouso -, através da reprodução de semelhanças imitativas ou através da cópia com o modelo a priori. A repetição-reprodução das instantaneidades repercutiu-se necessária para mostrar as amarras da linguagem e para criar novas visibilidades a estes repousos da docência.

\section{Docência-contemplação}

O pensamento platônico prevê um primeiro dualismo entre a essência inteligível e a aparência sensível, estruturando uma hierarquia entre esses dois campos de saber - em que o conhecimento e a ciência pertencem somente ao campo do inteligível - ao mundo das Ideias e se configuram pela superioridade da filosofia em relação aos outros saberes. Para o pensamento platônico, não pode haver verdadeiro conhecimento do sensível, pois o que pertence ao domínio do sensível é a opinião, que de nada tem de ciência, e é a matéria - que são cópias (semelhantes ao modelo ideal) ou simulacros (sem semelhança com o modelo). 
Mostra-se conflituosa essa relação entre ideia e cópias, já que há um lado puro e outro não, o lado do Ser e outro do semelhante, o lado da verdade e outro da aparência, respectivamente. O lado do céu e outro do solo. O lado do fundamento e outro da fundação. $\mathrm{O}$ método da dialética auxiliava na elevação do espírito até o conhecimento da essência do ser. O espírito eleva-se até o fundamento a partir das cópias-ícones que o campo do sensível nos apresenta. A inteligibilidade de uma coisa, no entanto, é dada pelo afastamento do sensível, visto que é somente por meio deste afastamento que se chega ao princípio universal. (PLATÃO, 2018). Quanto mais afastado da experiência sensível, no sentido ascendente, mais se torna possível conhecer o mundo transcendente, conhecer a identidade mesma das coisas. A teoria defendida pelo pensamento platônico é dirigida para uma realidade abstrata e ideal que tende a superar a experiência concreta e, portanto, passa a ser vista como contemplação e meditação. É por meio do processo de abstração que superamos a experiência sensível e conhecemos o sentido eterno e imutável das formas. As formas desde sempre prontas e acabadas e, portanto, passíveis apenas de contemplação.

A imagem da Docência que se atualiza na contemporaneidade muito carrega desta imagem-contemplação-socrático-platônica. Para compor a imagem da Docênciacontemplação alguns conceitos serão mobilizados, quais sejam: experiência, teoria, dialética, devir, ser, imutável, identidade, entre outros. Esses conceitos serão mobilizados no interior das amarras do plano de referência socrático-platônico que transbordam sentidos bem definidos e que funcionam como abcissas e ordenadas do plano cartesiano da Docência contemporânea, pontos ou instantaneidades, tais como a docência-lúdica, docênciaconstrutivista, docência-seja-lá-o-que-for. O que se pretende é remontar o plano de referência da Docência em matemática, é mapear seus territórios e definir seus sentidos.

A Docência é aqui entendida por meio de opiniões e pretende-se remontar seu plano de referência a partir de três necessários questionamentos: a) Quais são as opiniões que se tem sobre a Docência em matemática? Que imagem é atualizada quando se pensa a Docência em matemática? b) Quando se quer conhecer a Docência e dela viver, o que é preciso fazer? Como formar um conhecimento sobre a Docência, no que tange aos campos de formação de professores de matemática? c) Como reconhecer a verdadeira Docência? Quem é a Docência em matemática?

Estas questões colocam-se como problemas filosóficos, visto que as soluções serão inventadas. As opiniões se apresentam em caixas de texto com fundo cinza, e se configuram 
pelas respostas dadas por 47 licenciandos em Matemática de duas Instituições de Ensino Superior do RS.

Soluções para os problemas filosóficos:

a) Quais são as opiniões que se tem sobre a Docência em matemática? Que imagem é atualizada, quando se pensa a Docência em matemática?

A imagem da Docência em matemática que se pode destacar está intimamente relacionada com a proximidade entre as noções de docência, docente e discente. O que se pode constatar é que não há Docência sem docente e sem discente, assim como não há a Virtude sem homens justos em suas ações com outros; o docente e o discente são apenas dados da experiência que se pretende extrapolar. E ainda, a Docência não é o docente e nem é o discente, nem está num docente e nem está num discente, mas se faz na relação hierarquizada entre ambos. O docente e o discente são seres sensíveis em devir e, portanto, a Docência se configura na seleção dos verdadeiros pretendentes nesta relação.

Docência - relação benevolente:

"É questão de vocação e força de vontade. É ser paciente, prestativo, saber passar o que aprendeu, de modo que o seu aprendiz não se desinteresse pelo assunto a ser ensinado. A docência é a arte de doar a ciência e fazer o outro, mesmo que esse outro seja uma pessoa mais experiente na vida, entender algo que a esse outro não era inteligível. Ser docente vai muito além de uma profissão; é formar cidadãos capazes de fazer a diferença na sociedade e no mercado de trabalho. É ser a principal ferramenta de educação e transformação de uma nação. É a fonte de prosperidade da raça humana. Uma pessoa que tenha paciência em ensinar, não faça com que o aluno desanime de procurar mais conhecimento; é um amigo que o aluno pode procurar para tirar suas dúvidas e não ter vergonha de efetuar perguntas. Alguém muito importante para a educação do país; é fazer algo que é prazeroso em prol do próximo, ver que o resultado é maravilhoso. É a realização do sonho conquistado, é ser importante na vida do próximo, mesmo que com um simples gesto. Ser docente é estar atento à vida e à transformação dela, é se doar por um propósito, ser digno, mostrar o caminho. Defino docência como algum tipo de vocação, um talento nato, como o talento de um artesão ao criar seus objetos. Ser professor é uma dádiva, é muito mais que um dom. Ser professor é ser pai, mãe, família, é transmitir para os seus alunos alegria, carinho, dedicação, respeito, compreensão e, sobretudo, amor. Ser professor é uma paixão e entrega total.” (Vozes dos 47)

Docência em matemática se configura, portanto, como uma ciência (um conhecimento) que, pretensiosamente boa, não procura nem prescreve a vantagem do mais forte, neste caso, do docente; mas sempre a vantagem do mais fraco, que lhe é sujeito, o aluno (PLATÃO, 2018). Logo, o sujeito da Docência é o discente e o objeto da Docência, o docente? 
O docente, à vista dessas opiniões, não passaria de um homem de bem que, como homens de bens que são, "não querem governar nem pelas riquezas nem pela honra; porque não querem ser considerados mercenários, exigindo abertamente o salário correspondente à sua função, nem ladrões, tirando dessa função lucros secretos” (PLATÃO, 2018, p. 38).

Logo, o docente é o objeto da docência, é o que se quer e o que se pretende conhecer. O objeto das opiniões é sempre a mutabilidade, o devir, o que perece com o tempo. Em contraposição, o papel da inteligência é conhecer o seu objeto para ascender à essência da Docência - que ultrapassa a opinião.

A Docência também se configura como um ato de transmissão de conhecimento, como ensino da verdade necessária e útil ao bem viver do cidadão.

Compromisso com a Verdade:

"A docência nada mais é do que a arte de transmitir conhecimento e dar habilidade racional a alguém que não os possui ainda, com paciência, dedicação e, por que não, aprimoramentos do seu próprio saber, para assim poder ensinar. É saber também aprender a ensinar. Docência é a arte de transmitir o conhecimento, contribuindo para o acréscimo da sabedoria. $\mathrm{O}$ principal intuito da docência é dar condições para que o aluno construa seu conhecimento. $\mathrm{O}$ professor tem que, principalmente, fazer o aluno perceber que é preciso questionar sobre tudo nesta vida. O professor é formador de opinião, logo, postura e responsabilidade não podem deixar de estarem sempre presentes. Ato de passar informações para outro indivíduo, ensinando e incentivando o crescimento pessoal e pedagógico do aluno." (Vozes dos 47)

O aspecto dialético da relação docente-discente se configura na representação de poder ou de superioridade no reconhecimento da transmissão do conhecimento de "um" para o "outro", respectivamente. O docente, portanto superior ao discente, teria a sabedoria das Ideias e, por meio da arte metodológica da dialética, auxiliaria seu discípulo a sair do mundo das aparências para lembrar-se das essências. Entre posições contrárias e incentivadas pelo docente, o discente poderá alcançar o conhecimento. No entanto, o docente deverá estar bem preparado quanto à sua tarefa de conduzir a conduta do outro em prol da verdade e poderá se utilizar de figuras que modelam ou desenham, e que produzem sombras e seus reflexos nas águas, para tentar que seu discípulo veja esses objetos em si mesmos, que, de outro modo, só podem ser percebidos pelo pensamento (PLATÃO, 2018). A imagem da Docência em matemática que se atualiza ainda está configurada na relação conflituosa que se estabelece entre docente e discente, visto que a Docência se atualiza como o ato da "transmissão", do “ensinar", do "dar condições”, do "dar informações" ao discente para que este, por intermédio 
da inteligência, alcance o (re)conhecimento verdadeiro das coisas. Na imagem-contemplaçãosocrático-platônico,

denominas conhecimento discursivo, e não inteligência, a geometria e outras ciências do mesmo gênero, considerando esse conhecimento intermediário entre a opinião e a inteligência. [...] Aplica agora a estas quatro seções estas quatro operações da alma: a inteligência à seção mais elevada, o conhecimento discursivo à segunda, a fé à terceira, a imaginação à última; e dispõe-nas por ordem de clareza, partindo do princípio de que, quanto mais seus objetos participam da verdade, mais eles são claros (PLATÃO, 2018, p. 295).

O desenvolvimento da inteligência do discente, portanto, ocupa uma preocupação primordial na relação docente-discente, ou seja, a Ideia de Docência possui como cópiaícones aquelas relações docente-discente em que o docente pretende desenvolver a inteligência do discente para que os objetos de conhecimento sejam clarificados. A inteligência, então, selecionará os objetos que se assemelham ao modelo suprassensível passível apenas de contemplação, visto já estarem prontos e acabados, assim como a relação docente-discente se assemelha ao modelo de Docência-Repouso $\mathrm{D}(\mathrm{x})$. Logo, nenhuma relação docente-discente é essencialmente Docência, pois a Docência é essencialmente permanente e a relação docente-discente não é.

Para Platão, o devir é ele próprio um devir ilimitado, um devir louco, um devir hybrico e culpado que, para ser colocado em círculo, precisa sofrer a ação de um demiurgo que o envergue pela força, que lhe imponha o limite ou o modelo da idéia; o devir ou o caos são repelidos para o lado de uma causalidade mecânica obscura e o ciclo é referido a uma espécie de finalidade que se impõe de fora: o caos não subsiste no ciclo, o ciclo exprime a submissão forçada do devir a uma lei que não é a sua (DELEUZE, 1976, p. 22).

O devir louco da relação docente-discente só pode assemelhar-se com a Docência - e não, ser a Docência - na medida em que alguns limites forem impostos. A essência da relação docente-discente, porém, é mudar e, nesta imagem-contemplação, ela é regulada, ordenada e filtrada por uma lei de permanência e idealidade que não é a sua, a lei $\mathrm{D}(\mathrm{x})$ - Docênciarepouso.

A imagem da Docência que também é atualizada é aquela que se dedica à metodologia da dialética no sentido de uma ascensão do conhecimento à verdade última das coisas.

Metodologia da Dialética:

"Para ser docente, precisamos saber ouvir, dialogar e interpretar os conhecimentos do nosso cotidiano. É dedicar-se a ensinar e colaborar educacionalmente com o crescimento e desenvolvimento da sabedoria humana. Ser docente é reter um conhecimento com o intuito 
de juntar muitas pessoas e difundir esse conhecimento para tornar, de uma forma mesmo que pequena, o mundo desse grupo melhor. A docência é a arte de transferir conhecimento, aprender e ensinar diariamente. Professor é compromisso, responsabilidades, é verdade, é tudo." (Vozes dos 47)

Saber ouvir, dialogar para juntar pessoas e difundir conhecimento parece mesmo ser a pretensão da dialética da Docência na imagem-contemplação-platônica. Acrescenta-se a tudo isso o compromisso com a verdade, que é última e deve ser alcançada, pois não está no âmbito deste mundo sublunar das opiniões e da matéria louca. Por outro lado, elevar a opinião do discente à inteligência é um processo bastante difícil, visto que o discente não está habituado à claridade das essências.

E se o arrancarem à força da sua caverna, o obrigarem a subir a encosta rude e escarpada e não o largarem antes de o terem arrastado até a luz do Sol, não sofrerá vivamente e não se queixará de tais violências? E, quando tiver chegado à luz, poderá, com os olhos ofuscados pelo seu brilho, distinguir uma só das coisas que ora denominamos verdadeiras? (PLATÃO, 2018, p.298).

E esse processo de elevação não pode ser violento a ponto de largar o discente sozinho com os olhos ofuscados pela claridade do mundo inteligível, assim como não se podem largar sozinhos os prisioneiros de uma caverna escura quando se deparam com a luz solar. A Docência em matemática ou Docência-contemplação, nesse sentido, é

A arte que se propõe este objetivo, a conversão da alma, e que procura os meios mais fáceis e mais eficazes de o conseguir. Não consiste em dar visão ao órgão da alma, visto que já a tem; mas, como ele está mal orientado e não olha para onde deveria, ela esforça-se por educá-lo na boa direção (PLATÃO, 2018, p. 302).

A Docência-contemplação exige do docente uma dedicação e um compromisso com o desenvolvimento da sabedoria de seu discípulo. Quanto à ascensão da alma e à contemplação dos objetos no plano inteligível,

a idéia do bem é a última a ser apreendida, e com dificuldade, mas não se pode apreendê-la sem concluir que ela é a causa de tudo o que de reto e belo existe em todas as coisas; na mundo visível, ela engendrou a luz e o soberana da luz; no mundo inteligível, é ela que é soberana e dispensa a verdade e a inteligência; e é preciso vê-la para se comportar com sabedoria na vida particular e na vida pública (PLATÃO, 2018, p. 300). 
Conclui-se, portanto, que a representação da Docência em matemática que se configura por intermédio de opiniões se atualiza pela imagem-contemplação-socráticoplatônica: Docência-contemplação.

Sobretudo importante: i) A Docência é a forma ideal - habita o mundo das Ideias. ii) A Docência não é passível de experimentação, apenas de contemplação. iii) A Docência é anterior - a priori - à própria experiência. iv) A Docência não é o docente, nem é o discente, nem é a relação docente-discente. v) A Docência não é predicado do docente nem do discente: é o que se quer atingir, pois está no plano transcendental. vi) A relação docente-discente é um devir louco, dados da experiência que se pretende extrapolar. vii) A relação docente-discente será cópia-ícone da Docência quando for boa e assemelhar-se ao modelo a priori. viii) Existem falsos pretendentes da Docência quando a relação docente-discente não mantiver semelhança com o modelo. ix) A dialética é o método da Docência-contemplação. x) A Docência é a verdade que deve ser alcançada.

b) Quando se quer conhecer a Docência em matemática e dela viver, o que é preciso fazer? Como formar um conhecimento sobre a Docência, no que tange aos campos de Formação de Professores de Matemática?

A Docência-Contemplação, como forma, é a condição de possibilidade da atividade docente, visto pretender encarnar-se na experiência (atividade) dele, visto necessitar de matéria para efetuar-se, visto ser a forma ideal suprassensível a que se quer ascender. Logo,

\section{Docência $\neq$ Docente}

mas, por vezes, a atividade docente carrega semelhanças externas com a identidade.

Há, portanto, um paradoxo da Docência: A Docência é o a priori, ou a causa da atividade docente, pois é a forma que se encarna na matéria. Por sua vez, a atividade docente é o efeito de uma causa que lhe é externa e que possui contornos bem definidos. Busca-se a idealidade da Docência na atividade do docente que, no máximo, será cópia do modelo nunca será a Docência-contemplação. Justamente: não se pode buscar a Docência na atividade docente, porque somente esta é idêntica a ela mesma. A Docência, porém, só possui existência se encarnar-se em tal atividade.

O docente só será considerado um bom docente se sua experiência assemelhar-se ao modelo de Docência que se pretende ideal, mas nunca será capaz de se igualar. Então se espera a Docência universal de docentes particulares.

\section{Docência $\approx$ Docente}


Para que o docente particular conheça e ascenda à Docência é necessário que ele contemple as prescrições ditadas pelo que seja a Docência desejável. A Docência prescrita e desejável que pretende ser contemplada pelo docente é a Ideia: do tipo que só a justiça é justa, e só a coragem corajosa. A docência-lúdica, docência-construtivista, docência-crítica, docência-tecnológica, docência-interdisciplinar, docência-reflexiva, docência-identidade, docência-seja-lá-o-que-for são, portanto, apenas parcelas extensas de uma soma infinita que tem a pretensão de chegar à totalidade da forma da Docência-Contemplação. Logo, nem a soma das parcelas, nem as próprias parcelas extensas da Docência-contemplação são a Docência-contemplação, pois esta é a natureza última e essencial da realidade. Sendo assim, a Docência pode ser uma tarefa impossível ao docente. Ou melhor, possível sim, mas apenas ao pós-morte docente.

c) Como reconhecer a verdadeira Docência? Quem é a Docência em matemática?

Pretende-se selecionar uma linhagem pura da Docência-contemplação a partir de material impuro, no caso, a partir da atividade docente. Do universal ao particular, ou seja, do que se prescreve e se dita como a verdadeira e a ideal Docência até os seus assemelhamentos (docência-crítica, docência-construtivista, docência-interdisciplinar, docência-reflexiva, docência-lúdica, docência-identidade, docência-tecnológica, docência-seja-lá-o-que-for).

Percebe-se, na Docência-Contemplação, a predominância da teoria (enquanto forma abstrata) em detrimento da experiência prática, reinaugurando e imperando, na imagem da Docência em matemática na contemporaneidade, um racionalismo técnico. Imagem platônica que ainda prevalece na formação inicial de professores de matemática.

\section{Docência-generalização}

Aristóteles define o método analítico como aquele método que se preocupa com a demonstração. Para deduzir o que é o ser (a essência das coisas), parte-se de premissas verdadeiras e, a partir dessas partes, constitui-se o ser, o todo absoluto. As premissas falsas também são consideradas, mas somente para validar as verdadeiras e, posteriormente, serem eliminadas do processo de dedução. Através da eliminação, garante-se a validez dos resultados. Ao contrário do método platônico, o método dual aristotélico leva em consideração o lado negativo do binarismo: é o método da contradição. Há um 'a' e um 'nãoa'.

O que é dado ao sujeito, por meio da sensibilidade, é o objeto, mas esse objeto só poderá ser pensado de maneira silogística, necessitando de mediação. No modo silogístico de 
pensar, dado um conceito "a razão procura um meio-termo, isto é, outro conceito que, tomado em toda a sua extensão, condicione a atribuição do primeiro conceito a um objeto" (DELEUZE, 2000, p. 26).

Pautada no pensamento aristotélico "apresentar aos sentidos, de uma maneira atual e concreta, a imagem de uma coisa irreal, ausente ou impossível de perceber diretamente" (LALANDE, 1999, p. 955) é o que generaliza a conflituosa relação entre a matéria e a forma, e o que se percebe, sobretudo, é a prevalência da experiência prática por meio dos sentidos sobre a forma. O sensível é importante, mas está na fundação e só é um meio de elevar o conhecimento até a abstração do conceito, no fundamento, em um caminho que vai do particular ao geral. Generaliza-se o conceito através da observância das semelhanças entre os particulares materiais. Portanto, necessita-se de um sujeito e seus sentidos para, por meio da inteligência, reconhecer as similitudes imitativas de um particular a outro e, dessa forma, abstrair a generalidade e fazer valer a forma, por dedução, para particulares que extrapolam os sentidos. A coisa, aquilo que se apresenta ao sujeito por meio do sensível, não é o que parece ser, é um misto de matéria e forma. Há um lado, o lado da forma, que não se apresenta de imediato ao sensível, mas somente à razão por meio da abstração.

A imagem da Docência que se atualiza na contemporaneidade muito carrega desta imagem-generalização-por-dedução-e-abstração-aristotélica. Para compor a imagem da Docência-Generalização alguns conceitos serão mobilizados, quais sejam: experiência, teoria, prática, dialética, devir, ser, imutável, identidade, entre outros. Esses conceitos serão mobilizados no interior das amarras do plano de referência aristotélicos, que transbordam sentidos bem definidos e funcionam como abcissas e ordenadas do plano cartesiano da Docência contemporânea, pontos ou instantaneidades, tais como a docência-colaborativa, docência-coletiva, docência-compartilhada, docência-seja-lá-o-que-for.

A Docência é aqui reconhecida por meio da matéria, por meio da multiplicidade, por meio de docências (atividades docentes) particulares em devir, e se pretende remontar seu plano de referência a partir de três necessários questionamentos: a) Quais são as premissas verdadeiras que se tem sobre a Docência em matemática? Que imagem é atualizada quando se pensa a Docência a partir do método analítico-aristotélico? b) Quando se quer conhecer a Docência em matemática e dela viver, o que é preciso fazer? Como formar um conhecimento sobre a Docência, no que tange aos campos de formação de professores de matemática? c) Como reconhecer a Docência? $O$ que é a Docência em matemática? 
Essas questões colocam-se como problemas filosóficos, visto que as soluções serão inventadas. As premissas verdadeiras se apresentam em caixas de texto com fundo cinza, e se configuram por levantamento bibliográfico em livros que fazem parte das referências básicas na área da Formação de Professores de Matemática, perspectivado pela Educação Matemática. Os livros foram escolhidos porque compuseram as bibliografias básicas de disciplinas de Educação Matemática ministradas por esta professora na graduação em licenciatura em matemática.

Soluções para os problemas filosóficos:

a) Quais são as premissas verdadeiras que se tem sobre a Docência em matemática? Que imagem é atualizada quando se pensa a Docência a partir do método analíticoaristotélico?

Não há como negar que a imagem da Docência contemporânea está intimamente relacionada, ora como causa, ora como efeito, com a noção de docente. O que se pode constatar é que não há Docência sem docentes particulares.

\section{Docência-coletiva:}

"O trabalho coletivo também possui outra característica fundamental: a manutenção da singularidade de cada um de seus membros. Mesmo as professoras participando das mesmas reuniões de planejamento, cada uma manteve sua singularidade; cada docente, sem perder construindo a própria prática, sem perder a subjetividade." (NACARATO, 2005, p. 185).

Docência-colaborativa:

"[...] se houver realmente em um lugar em que todos assumem o desafio de aprender uns com os outros, se houver, intercâmbio entre os professores [...]" (FREITAS et al., 2005, p. 104).

Docência-compartilhada:

"[as professoras] consideram importante o intercâmbio de projetos, com ampla divulgação dos sucessos e fracassos. Mas, para isso, é preciso uma boa liderança -gestores totalmente democráticos -, que incentive e mobilize os professores para a mudança compartilhada." (FREITAS et al., 2005, p. 103).

A definição de Docência-Generalização é considerada, por ora, como uma noção demasiada geral. Predicamos o gênero "Docência-Generalização" de um docente particular; entretanto, "Docência-Generalização" não está em um sujeito docente particular. O que vale para o gênero também vale para as espécies (docência-colaborativa, docência-coletiva, docência-compartilhada, docência-cooperativa etc.), pois afirma-se também a "docênciacolaborativa" deste ou daquele grupo de docentes em particular, mas ela também não pode ser 
encontrada neles. A definição da espécie e a do gênero é usada referindo-se a um indivíduo humano particular, o docente. Portanto, a substância não se encontra num sujeito (ARISTÓTELES, 2010).

Com base na lógica de especificação aristotélica, torna-se uma qualificação mais pertinente e própria mencionar a espécie do que o gênero. Seguindo neste rastro, a DocênciaGeneralização criou espécies para seu gênero. Torna-se, portanto, mais apropriado, conveniente e específico definir esta ou aquela atividade docente através da espécie do que do gênero. E nenhuma espécie é mais substância do que outra, pois cada espécie possui diferenças específicas e, portanto, elas não possuem contrários e nem são contrárias.

Não é do uno, com efeito, mas do múltiplo, que predicamos 'animal', 'homem'. A espécie e o gênero, contudo, não se limitam a indicar qualidade, como 'branco' indica meramente qualidade. O acidental, ou seja, como 'branco', significa pura e simplesmente uma qualidade. Mas a espécie e o gênero determinam uma qualidade com referência à substância. Informam qual o tipo de substância. No que respeita ao gênero, contudo, tal qualificação determinada cobre um campo muito mais amplo do que cobre no que tange à espécie. (ARISTÓTELES, 2010, p. 47).

Se dissermos 'Docência-Generalização', abarcamos mais do que abarcaríamos se disséssemos 'docência-colaborativa'. Não é do uno e do singular que a DocênciaGeneralização é definida, mas do múltiplo. A definição ou significado de DocênciaGeneralização se aplicará a uma atividade docente particular de maneira análoga. Portanto, a Docência-Generalização não é a atividade docente e nem está numa atividade docente.

A diferença entre a imagem da Docência-Contemplação e da Docência-Generalização é que a primeira é anterior à experiência e a segunda é um conhecimento a posteriori, resultado da experiência que considera o devir como substância para, por contradição, definir as premissas verdadeiras.

Conclui-se, portanto, que a representação da Docência que se configura por intermédio de premissas verdadeiras se atualiza pela imagem-aristotélica-generalização-por-abstração. Sobretudo importante: i) A Docência é passível de generalização. ii) Atividades docentes são um misto de matéria e forma. iii) Tanto a matéria quanto a forma são realidades; mas apenas a forma é imutável. iv) A Docência não é a atividade docente, mas necessita de atividades docentes particulares para ser reconhecida. v) Busca-se, erroneamente, encontrar a verdadeira Docência numa atividade docente particular. vi) A Docência-generalização não é predicado do docente nem do discente: é a generalidade de atividades docentes. vii) A relação entre 
atividades docentes se configura por um devir louco, dados da experiência que se pretende estabilizar pela abstração dos assemelhamentos, numa lei. viii) A Docência-generalização é forma. ix) Por contradição, pode-se perceber o que não é Docência. x) A Docência é a verdade que deve ser abstraída da matéria cambiante.

b) Quando se quer conhecer a Docência em matemática e dela viver, o que é preciso fazer? Como formar um conhecimento sobre a Docência, no que tange aos campos de Formação de Professores de Matemática?

Para compor a Docência-Generalização partiu-se de silogismos dialéticos, ou seja, partiu-se de opiniões de aceitação geral sobre como deve ser a Docência (colaborativa, coletiva, compartilha etc.), que geram conviç̧ão, que são aquelas que "se baseiam no que pensam todos, a maioria ou os sábios, isto é, a totalidade dos sábios, ou a maioria deles, ou os mais renomados e ilustres entre eles" (ARISTÓTELES, 2010, p. 348).

Nota-se, analogamente, o mesmo método de silogismo dialético em encontros entre docentes particulares que se propõem a viver a docência-colaborativa, docênciacompartilhada, docência-coletiva, docência-seja-lá-o-que-for; ou seja, nos encontros entre docentes, "tendo elencado as opiniões da maioria" (ARISTÓTELES, 2010, p. 350), generaliza-se o que é a Docência a partir dos assemelhamentos entre estas opiniões, "nos facultando mudar o curso de qualquer argumento que nos pareça estarem utilizando erroneamente" (ARISTÓTELES, 2010, p. 350).

c) Como reconhecer a Docência? O que é a Docência em matemática?

[...] quando pudermos argumentar que as coisas são idênticas ou que são distintas, estaremos [...] bem abastecidos de argumentos para trabalharmos também com definições, pois quando demonstrarmos que uma coisa não é idêntica à outra, teremos destruído a definição. $\mathrm{O}$ inverso, contudo, do que acabamos de declarar não tem validade, pois não basta à construção de uma definição mostrar que uma coisa é idêntica à outra; mas para destruir uma definição basta mostrar que não é idêntica. (ARISTÓTELES, 2010, p. 352).

A Docência-Generalização é a forma imutável de atividades docentes particulares em devir, tais como a docência-coletiva, docência-colaborativa etc., mas necessita de atividades docentes para existir, porém, ela não perece no tempo como essas experiências. Do particular ao geral, ou seja, das similitudes imitativas entre os particulares à abstração da $\mathrm{D}(\mathrm{x})$, ou seja, da Docência-repouso.

Percebe-se, na Docência-Generalização, a predominância da experiência, da atividade docente, em detrimento da teoria, pois a generalidade só é possível a partir de exemplares em 
devir, reinaugurando e imperando, na imagem da Docência na contemporaneidade, um racionalismo prático.

O que não se pode negar é que tanto na Docência-contemplação quanto na Docênciageneralização a forma pretende-se atemporal e encarna-se na matéria. Por este motivo, pelo primeiro dos dualismos, é que ambas as Docências compõem o conceito de Docênciarepouso. A diferença, enquanto conceito, não é pensada: ora é negada porque é dessemelhante ao modelo, ora é insuficiente porque não possui características semelhantes. A matéria cambiante, com seus diferenciais, deverá ser selecionada ou ordenada segundo uma lei formal $\mathrm{D}(\mathrm{x})$ que serve como boa medida, ou seja, pretende-se que o movimento da matéria seja interrompido para que a inteligência a capture. O problema ou o maldito da Docência-repouso é o diferente, o que varia, é o movimento. Pretende-se estabilizar o movimento por meio de instantâneos A, B, C especificados pelo pós-hífen, como se pudesse voltar a ele a partir de repetição de imobilidades. Porém, Bergson (2005, p. 333) alerta:

Instalem-se na mudança, vocês apreenderão ao mesmo tempo a mudança ela própria e os estados sucessivos nos quais ela poderia a todo instante imobilizar-se. Mas com esses estados sucessivos, percebidos de fora como imobilidades reais e não mais virtuais vocês nunca reconstituirão o movimento.

Instalem-se na mudança da docência e não em sua permanência. A mudança é o devir enquanto condição da docência movimento. De que modo se pode haver movimento senão a partir da variação da variação? A diferença é o que faz variar e, portanto, é o ser da docência movimento. A Docência-repouso, desta forma, apenas inaugura um falso movimento a partir da repetição-reprodução de seus infinitos instantâneos.

\section{Última atualidade da forma}

O aprisionamento da Docência em formas especificadas pelo pós hífen (docênciassejam-lá-o-que-for) comprova sua vontade de desacelerar para dar limite ao devir e determinar soluções a partir de necessidades que considera útil e acaba por retirar essas constantes de variáveis e fixá-las em instantaneidades (docência-lúdica, docência-colaborativa etc.). A repetição e a alternância destas determinações representariam o que seja o todo da Docência: uma atividade passível de ser reconhecida e reproduzida pelo docente. A racionalidade imposta pela Docência-repouso tenta fazer frente àquilo que é problema e que escapa da representação e das formas repouso previamente estabelecidas como ideais. Fazer 
frente significa servir como boa medida para regular a atividade docente, servir como modelo a ser imitado. Sugere, para o docente, repetir a regularidade.

$\mathrm{Na}$ Docência-repouso existe um erro lógico: pretende-se eternizar a Docência pela repetição-reprodução de suas soluções. No entanto, não são as soluções que persistem e que duram, mas o problema. O problema é que persiste. Prova disso é que há sempre outra nova necessidade de solução especificada pelo pós-hífen. Docência-lúdica, docência-crítica, docência-coletiva etc. não são soluções enquanto criações, mas instantaneidades congeladas que não resolvem definitivamente o problema da Docência, sendo apenas possibilidades irreais. Porém, "Para Bergson, criação não é escolha entre possíveis pré-estabelecidos, mas é invenção do novo, do que não preexistia a sua realização" (COELHO, 2004, p. 241). As docências-sejam-lá-o-que-for são os infinitos possíveis da Docência-repouso que preexistem à própria realização; a atividade do docente, contudo não possui diferencialidade na medida em que repete estas formas estacionárias, porque parte do assemelhamento com a forma instituída e se constitui apenas pela representação da Docência.

A Docência-repouso pretende-se diferencial por alternância entre distintos instantâneos não coexistentes. De que modo, porém, se pode querer movimento a partir de repetição de imobilidades? Há um falso movimento interrupto e descontínuo da forma da Docência instituído nessa racionalidade platônico-aristotélica, em que o todo da Docênciarepouso pretende ser reconstituído por suas partes, no entanto, pela soma de suas partes não se consegue estabelecer o todo. Então, o que se faz é especificar cada vez mais a matéria a fim de dar conta do todo. Entre uma determinação e outra, porém, há um “entre”, um intervalo, que assegura sua impossibilidade de completude.

As infinitas especificações que se configuram como soluções para a Docência, determinadas pelo pós-hífen, são resultado de uma tentativa de dar conta da diferença. Quando se depara com a diferença, captura-a em nova instantaneidade, a fim de que esta diferença seja regulada num futuro previsível. Por isso, existem essas muitas tentativas de estagnações da forma da docência, visto que se percebe que as imprevisibilidades que se sobressaem são consideradas o mal da docência, o negativo da atividade docente, aquilo que deve ser expurgado ou anulado ou limitado em uma nova forma segura e tranquila. No entanto, esta racionalidade apolínea que tenta encontrar e atingir a ordem e o equilíbrio, apenas causa aflição à atividade docente, pois concentra-se naquilo que a docência não é: ordenada. 
Impossibilitar a permanência da docência às definições prévias da DocênciaContemplação e às definições generalizadoras da Docência-Generalização consiste em assumir a aula em sua positividade, afirmá-la como causa e efeito, como condição da docência. Assumir a docência enquanto um movimento incessante é assumir que a docência possui a parcela da aula que constitui sua impossibilidade de permanência e que esta mesma parcela possibilita seu outramento, possibilita o seu movimento, portanto, parcela não negativa. A aula, enquanto parte disjunta e disforme da docência, escapa à representação por ser impossível de ser repetida como um experimento o pode ser. Inexprimível, a aula pode apenas ser vivida, assim como o próprio movimento o pode. Para que haja diferença na forma da docência que ela seja pensada em meio à vida, em meio à aula que está inserida na vida e que é puro movimento.

\section{Referências}

ARISTÓTELES. Órganon: Categorias, Da interpretação, Analíticos anteriores, Analíticos posteriores, Tópicos, Refutações sofísticas. 2. ed. Bauru, SP: Edipro, 2010.

BERGSON, Henri. A Evolução Criadora. São Paulo: WMF Martins Fontes, 2005.

COELHO, Jonas Gonçalves. Ser do tempo em Bergson. Interface - Comunicação, Saúde, Educação, Botucatu, v. 8, n. 15, p. 233-246, mar./ago., 2004.

CORAZZA, Sandra Mara. O docente da diferença. Periferia, Duque de Caxias, FEBF/UERJ, vol. 1, n. 1, p. 91-110, 2008.

CORAZZA, Sandra Mara. Currículo da Infância e Infầncia do Currículo: uma questão de imagem. In: PARAÍSO, Marlucy Alves; VILELA, Rita Amélia; SALES, Shirlei Rezende (Org.). Desafios contemporâneos sobre currículo e escola básica. Curitiba: CRV, 2012. p. 25-38.

DALAROSA, Patrícia Cardinale. Pedagogia da tradução: entre bio-oficinas de filosofia. 2011, 74 f. Dissertação (Mestrado em Educação) - Programa de Pós-Graduação em Educação, Faculdade de Educação, Universidade Federal do Rio Grande do Sul, Porto Alegre, 2011.

DELEUZE, Gilles. Nietzsche e a filosofia. Rio de Janeiro: Editora Rio, 1976.

DELEUZE, Gilles. Filosofia crítica de Kant. Lisboa: Edições 70, 2000.

DELEUZE, Gilles. Diferença e Repetição. Rio de Janeiro: Graal, 2006a. 
DELEUZE, Gilles. A Ilha deserta: e outros textos. São Paulo: Iluminuras, 2006b.

DELEUZE, Gilles. Lógica do Sentido. São Paulo: Perspectiva, 2009.

DELEUZE, Gilles. Bergsonismo. São Paulo: Ed. 34, 2012.

DELEUZE, Gilles; GUATTARI, Félix. O que é a filosofia? Rio de Janeiro: Ed. 34, 1992.

FOUCAULT, Michel. Microfísica do poder. Rio de Janeiro: Edições Graal, 1979.

FOUCAULT, Michel. Isto não é um cachimbo. Rio de Janeiro: Paz e Terra, 1988.

FOUCAULT, Michel. O que é um autor? In: FOUCAULT, Michel. Estética - literatura e pintura, música e cinema. Organização, seleção de textos e revisão técnica de Manoel Barros da Motta. Tradução de Abner Chiquieri. Rio de Janeiro: Forense Universitária, 19692015. p. 264-298. (Coleção Ditos e Escritos, v. III).

FREITAS, Maria Teresa Menezes et al. O desafio de ser professor de matemática hoje no Brasil. In: FIORENTINI, Dário; NACARATO, Adair Mendes (Org.). Cultura, formação e desenvolvimento profissional do professor que ensina matemática. São Paulo: Musa Editora, 2005. p. 89-105.

HEUSER, Ester Maria Dreher. Pensar em Deleuze: violência e empirismo no ensino da filosofia. Ijuí, RS: Unijuí, 2010.

LALANDE, André. Vocabulário técnico e crítico da filosofia. São Paulo: Martins Fontes, 1999.

NACARATO, Adair Mendes. A escola como lócus de formação e de aprendizagem: possibilidades e riscos da colaboração. In: FIORENTINI, Dário; NACARATO, Adair Mendes (Org.). Cultura, formação e desenvolvimento profissional do professor que ensina matemática. São Paulo: Musa Editora, 2005. p.175-195.

PLATÃO. A República. Disponível em:

<http://www.eniopadilha.com.br/documentos/Platao_A_Republica.pdf>. Acesso em: 30 jun. 2018.

SANTOS, Suelen Assunção. Docen ci/ç ação: do dual ao duplo da docência em matemática. 2015, 189 f. Tese (Tese em Educação) - Programa de Pós-Graduação em Educação,

Faculdade de Educação, Universidade Federal do Rio Grande do Sul, Porto Alegre, 2015.

SANTOS, Suelen Assunção; SANTOS, Gilberto Silva dos. Docências em educação matemática: composições estéticas... In: ANPED Sul - Reunião Científica da ANPED, 10, 2014, Florianópolis. Anais... Florianópolis: UDESC, 2014. Disponível em:

<http://xanpedsul.faed.udesc.br/arq_pdf/2024-0.pdf>. Acesso em: 27 maio 2018. 